\title{
SBAS-DInSAR monitoring of subsidence induced by extracting brine from an underground salt deposit in Tuzla, Bosnia and Herzegovina
}

\author{
I Nyoman Sudi Parwata ${ }^{1}$, Norikazu Shimizu${ }^{1}$, Bojana Grujić ${ }^{2}$, Sabid Zekan ${ }^{3}$, Ruža \\ Čeliković ${ }^{3}$, Edis Imamović ${ }^{4}$, and Ivan Vrkljan ${ }^{5}$ \\ ${ }^{1}$ Graduate School of Science and Engineering, Yamaguchi University, 2-16-1 Tokiwadai, 755-8611 \\ Ube, Yamaguchi Prefecture, Japan \\ ${ }^{2}$ Faculty of Architecture, Civil Engineering and Geodesy, University of Banja Luka, Bulevar vojvode \\ Stepe Stepanovića 77/3, 78000 Banja Luka, Bosnia and Herzegovina \\ ${ }^{3}$ Faculty of Mining, Geology and Civil Engineering, University of Tuzla, Univerzitetska 2, 75000 \\ Tuzla, Bosnia and Herzegovina \\ ${ }^{4}$ Municipality of Tuzla, ZAVNOBiH-a 11, 75000 Tuzla, Bosnia and Herzegovina \\ ${ }^{5}$ Faculty of Civil Engineering, University of Rijeka, Radmile Matejčić 3, 51000 Rijeka, Croatia
}

\begin{abstract}
Tuzla City, Bosnia and Herzegovina, is very famous for salt mining. The intensive extraction of brine from the underground salt deposit caused accumulative subsidence of up to $-12 \mathrm{~m}$ from 1956 to 2003 . It induced serious damage to residences, buildings, and infrastructures. Although the activity of brine extraction was officially stopped in 2007, reports of subsidence are still on-going for some areas of Tuzla City according to a previous study. In the present study, a satellite-based method, i.e., Differential Synthetic Aperture Radar (DInSAR), is applied for the subsidence monitoring of the induced underground brine extraction. Since October 2014, SAR data obtained by the Sentinel-1A and -1B satellites (European Space Agency: ESA) and Small Baseline Subset (SBAS) multi-temporal analyses have been employed to obtain the spatial distribution and the temporal transition of the land subsidence. The accuracy and effectiveness of the SBAS-DInSAR method are assessed and evaluated by using the real-time kinematic GNSS monitoring system. DInSAR detected that the subsidence is still on-going at a velocity of -36.4 $\mathrm{mm} / \mathrm{year}$ in some areas, especially in an area northeast of the center of the city. This study presents the validity and effectiveness of SBAS-DInSAR as a useful subsidence monitoring tool.
\end{abstract}

\section{Introduction}

Tuzla City, Bosnia and Herzegovina, is very famous for salt mining. Extensive salt mining was conducted during the years of 1956 to 1988 by extracting the brine from the

\footnotetext{
* Corresponding author: sudi_jbc@yahoo.com
} 
underground salt deposit [1]. This extensive brine extraction has caused the massive occurrence of subsidence. From 1956 to 2003, the subsidence was measured by traditional topographic survey method and it is found that subsidence had reached up to $-12 \mathrm{~m} \mathrm{[1]}$. The next subsidence monitoring was conducted by static GPS surveys four times, i.e., 2004, 2005, 2006, and 2007 [2,3]. These static GPS surveys generated spatial distribution of subsidence for three periods, i.e., 2004-2005, 2005-2006, and 2006-2007 [2]. The GPS results showed that, in general, the subsidence was decreasing [2, 3]. However, the subsidence is still on-going in some parts of Tuzla City, especially in the area near Pannonica Lake [2, 3].

The main purpose of this research is to monitor the present subsidence in Tuzla City by means of Differential Interferometry Synthetic Aperture Radar (DInSAR). A SAR dataset from the Sentinel-1A and $-1 B$ satellites is used in the DInSAR processing. The Small Baseline Subset (SBAS) time-series algorithm [4] is employed to generate the temporal transition and the spatial distribution of the subsidence. In addition, the validity of the subsidence measured by SBAS-DInSAR is evaluated using the subsidence measured by the kinematic GNSS monitoring system installed in Tuzla.

\section{History of subsidence in Tuzla}

Tuzla City is located in the northeast part of Bosnia and Herzegovina. The salt deposits of Tuzla are located below Tuzla City in an area about $2 \mathrm{~km}^{2}$ (Fig. 1a). It consists of five separated layers, which contain a salt deposit existed in syncline with one of the wings close to the surface of the city's center (Fig. 1b). The maximum thickness of the salt formation is about 600 meters, as shown in Fig. 1b. The vertical cross-section line, X-X', shows the composition of the ground layers of the salt deposit. It is composed of marl with clay and sandstones, bands marl, weak rock, salt, anhydrate, and peripheral leaching products (Fig. 1b).

The primitive exploitation of salt in Tuzla was done by natural brine and shallow salt water wells 6000 years ago in the Neolithic period. This fact was revealed through the discovery of the ceramic fragments of holders from $3500 \mathrm{BC}$ that were used to boil saltwater over hot charcoal [2].

The intensive extraction of salt water by the uncontrolled leaching method caused massive ground subsidence as well as damage to and the destruction of over 2000 buildings. The first geodetic surveys of subsidence monitoring were conducted in 1914; however, there were no significant applications of the compiled data. More systematic geodetic monitoring (traditional topographic surveys) was started in 1955; it was performed annually with 1500 benchmarks distributed within $5 \mathrm{~km}^{2}$ covering the most urbanized parts and their surrounding areas [1].

One analysis of the archive topographical data was conducted by [1] and revealed that the ground subsidence in area was up to -12 meters (Fig. 2) [1]. The next subsidence monitoring activities were conducted four times by means of static GPS surveys in 2004, 2005, 2006, and 2007 [2, 3]. The static GPS surveys generated spatial distribution of subsidence for three periods, i.e., 2004-2005, 2005-2006, and 2006-2007 [2, 3]. The results of those surveys showed that the subsidence was generally decreasing, and that the remaining subsidence area was located near Pannonica Lake and was occurring at a velocity of about $-10 \mathrm{~cm} /$ year $[2,3]$.

As a countermeasure to the subsidence process, the decision to decrease the salt exploitation was made. The gradual suspension of salt exploitation was carried out from March 2006 to May 2007. On May 29, 2007, salt mining activities were officially terminated [5]. As the subsidence still continues, however, continuous monitoring should be conducted. 


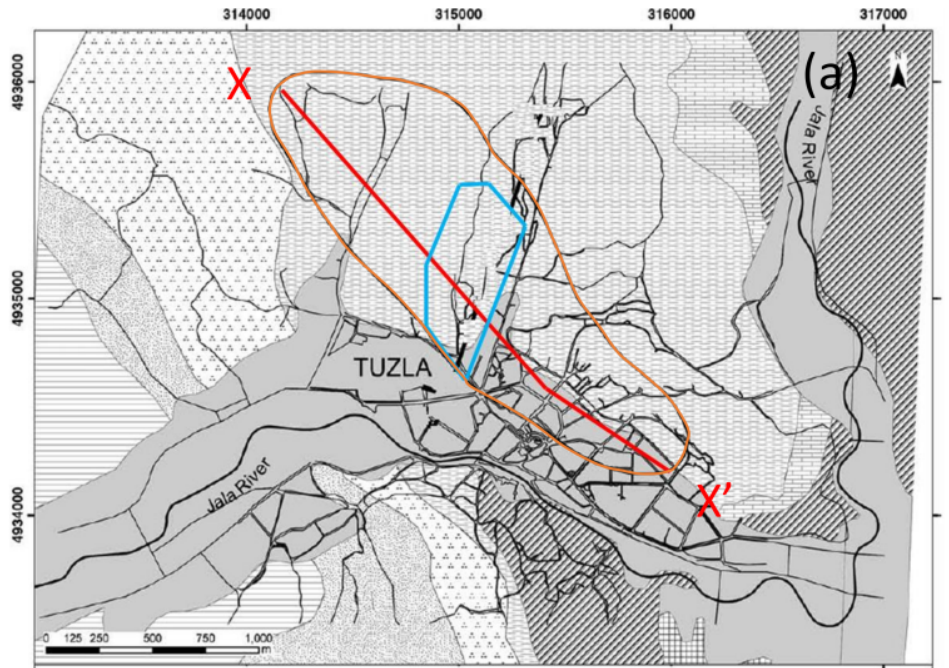

\section{Legend}

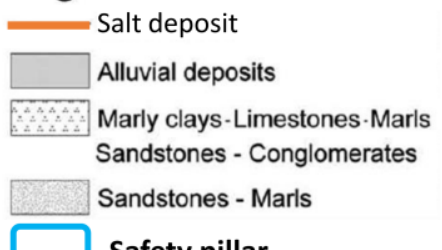

Safety pillar

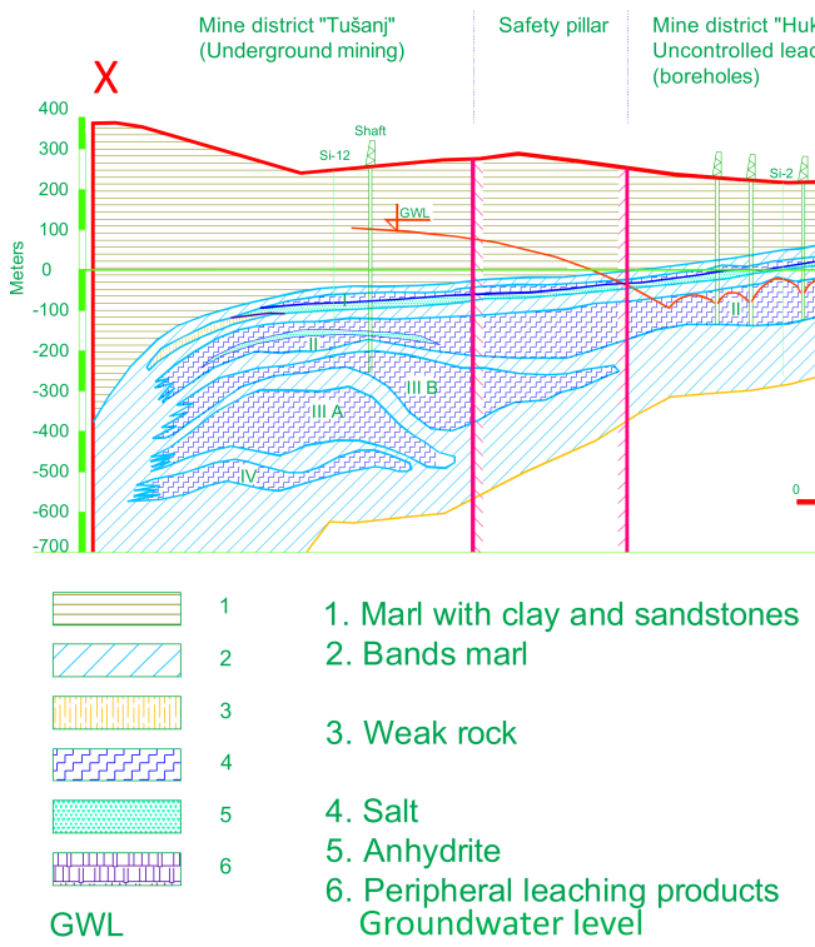

(b)

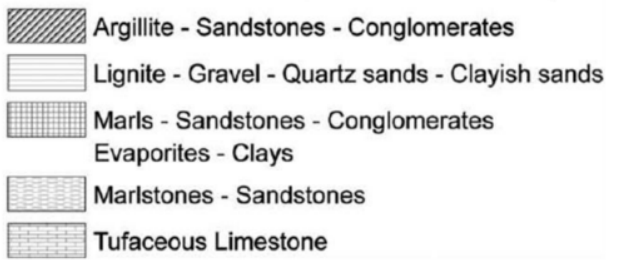



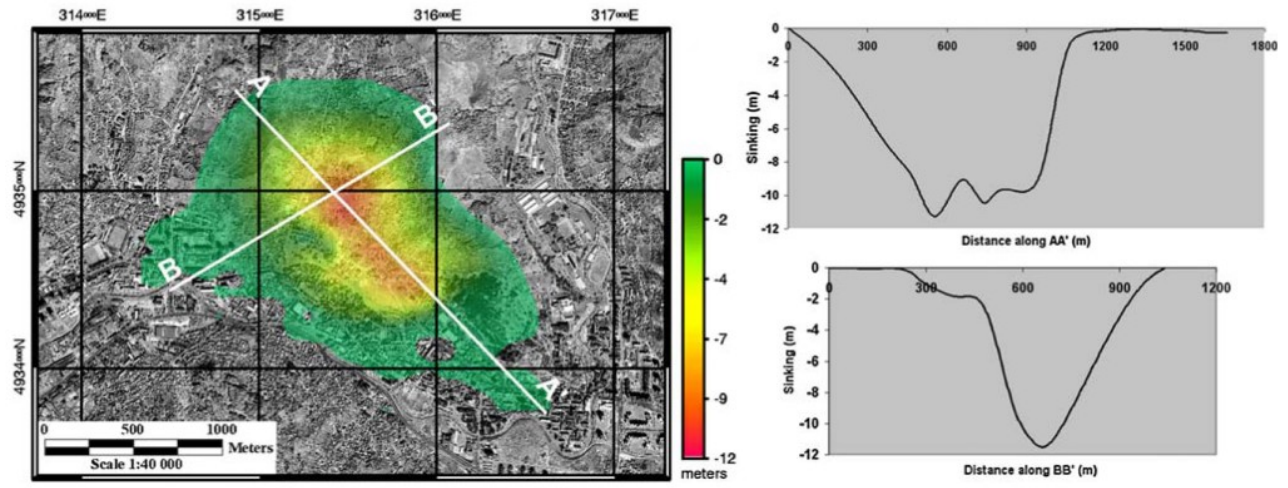

Fig. 2. Subsidence in Tuzla measured by traditional topographic surveys. Sections A-A' and B-B' present the maximum subsidence occurring along the selected directions [1].

\section{Application of SBAS-DInSAR to monitoring subsidence}

\subsection{Outline of DInSAR}

Synthetic Aperture Radar (SAR) in an active remote sensing imaging system mounted on an aircraft or artificial satellite. It transmits electromagnetic waves to the ground surface and receives the reflected waves from the ground surface. One of the principle applications of SAR is Differential Interferometry SAR (DInSAR). It is a technique for measuring the ground surface displacements over vast areas in the one-dimensional direction, i.e., LOS (line of sight) direction, with $\mathrm{cm}$ accuracy. DInSAR does not require the use of any devices in the area being monitored.

DInSAR is often used for monitoring ground surface displacements related to subsidence, landslides, and ground surface displacement brought about by earthquakes, volcanoes, etc. To conduct a DInSAR analysis, at least two sets of SAR data are required. Those SAR data are obtained from the same or an identical SAR system and measure the same area at different times (Fig. 3).

DInSAR processing requires topographical (Digital Elevation Model/DEM) information on the monitored area. The DEM is used in the process of topographic phase removal of DInSAR analysis. After removing the topographic phase and other errors (i.e., orbit inaccuracy, atmospheric delays, and noises), the ground surface displacements can be obtained [7].

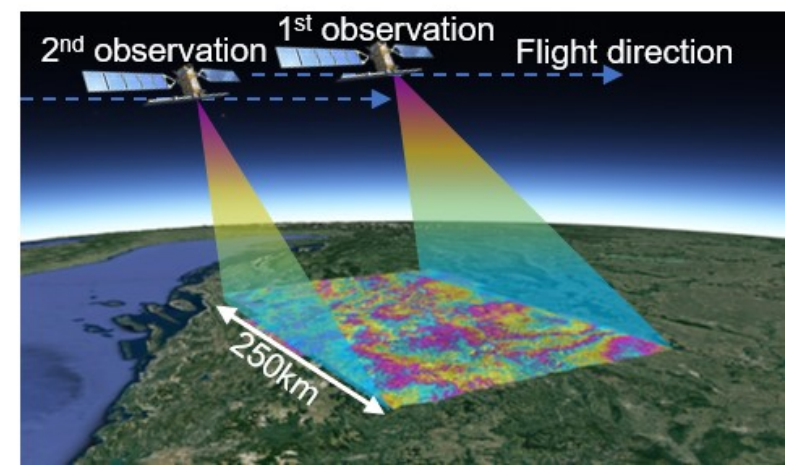

Fig. 3. Illustration of SAR satellites observing the Earth's surface from space. 


\subsection{SAR dataset}

The SAR dataset from Sentinel-1A and -1B satellites (European Space Agency: ESA) was employed in this research. The total number of SAR data used in this research is 199. The SAR data were taken from October 9, 2014 to May 28, 2019 in the descending orbit direction (Table 1). Since Sentinel-1A and -1B are in active operation, the amount of SAR data can be updated every 6-12 days.

Table 1. SAR dataset used in this research.

\begin{tabular}{|c|c|}
\hline Satellite name & Sentinel-1A and -1B \\
\hline Number of SAR data & 199 \\
\hline From (date) & October 9, 2014 \\
\hline To (date) & May 28, 2019 \\
\hline Orbit direction & Descending \\
\hline SAR sensor direction & Right-looking \\
\hline
\end{tabular}

\subsection{SBAS Method}

The Small Baseline Subset (SBAS) DInSAR multi-temporal analysis [4] is employed in this study. SBAS-DInSAR utilizes a series of SAR images and conducts multiple DInSAR processing to generate several interferograms. Multiple DInSAR processing is based on the possible SAR data pairs after applying a threshold for the spatial and temporal baselines. In this research, the temporal baseline threshold is 48 days, while the spatial baseline threshold is 250 meters. The thresholds produce the sets of combinations shown in Fig. 4.

Time-position plot

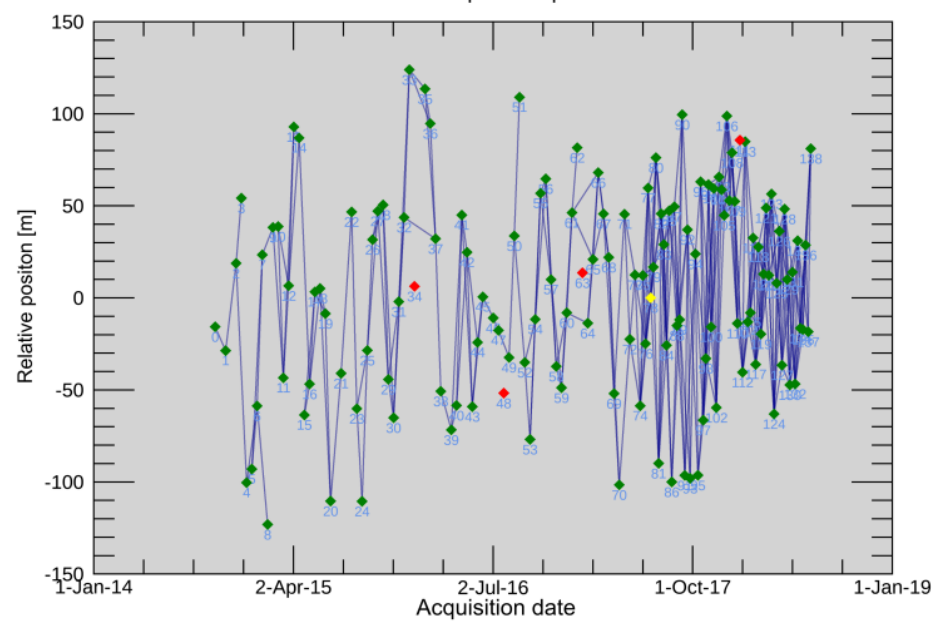

Fig. 4. Combinations of SAR pairs for the SBAS-DInSAR analysis. The green diamonds are the number of SAR data used in the SBAS-DInSAR analysis; the red diamonds are the SAR data that were not used.

After conducting the multiple DInSAR processing step, eight SAR images were removed due to low coherence. The green dots in Fig. 4 indicate the SAR data used in the SBAS-DInSAR analysis, while the red dots indicate the SAR data that were not used due to low coherence.

The ALOS World 3D 30-meter resolution (AW3D30) DEM, provided by the Japan Aerospace Exploration Agency (JAXA), is used in topographic phase removal process. Envi-SARscape 5.4 (sarmap) was used for the SBAS-DInSAR analysis. ArcGIS (ESRI) 
was used for the image analysis and the map generation. The displacement provided by SBAS-DInSAR is a one-dimensional component in the direction of the satellite's line of sight (LOS). The subsidence is obtained as the vertical component of the displacement, assuming that the horizontal displacement is very small and can be ignored.

\section{Results and Discussion}

\subsection{Spatial distributions of subsidence obtained by SBAS-DInSAR}

The spatial distributions of the subsidence obtained by SBAS-DInSAR are presented in Figs. 5a-e. The maps show the subsidence distribution from October 9, 2014 to May 28, 2019. The subsidence areas are indicated by yellow, orange, and red colors (negative values). They are scaled from $150 \mathrm{~mm}$ to $-150 \mathrm{~mm}$. The green color indicates the stable or non-subsidence areas. It is seen on the maps that the subsidence is mostly located northeast of Pannonica Lake. These results are similar to those of the GPS survey conducted from 2006 to 2007 (Fig. 5f).
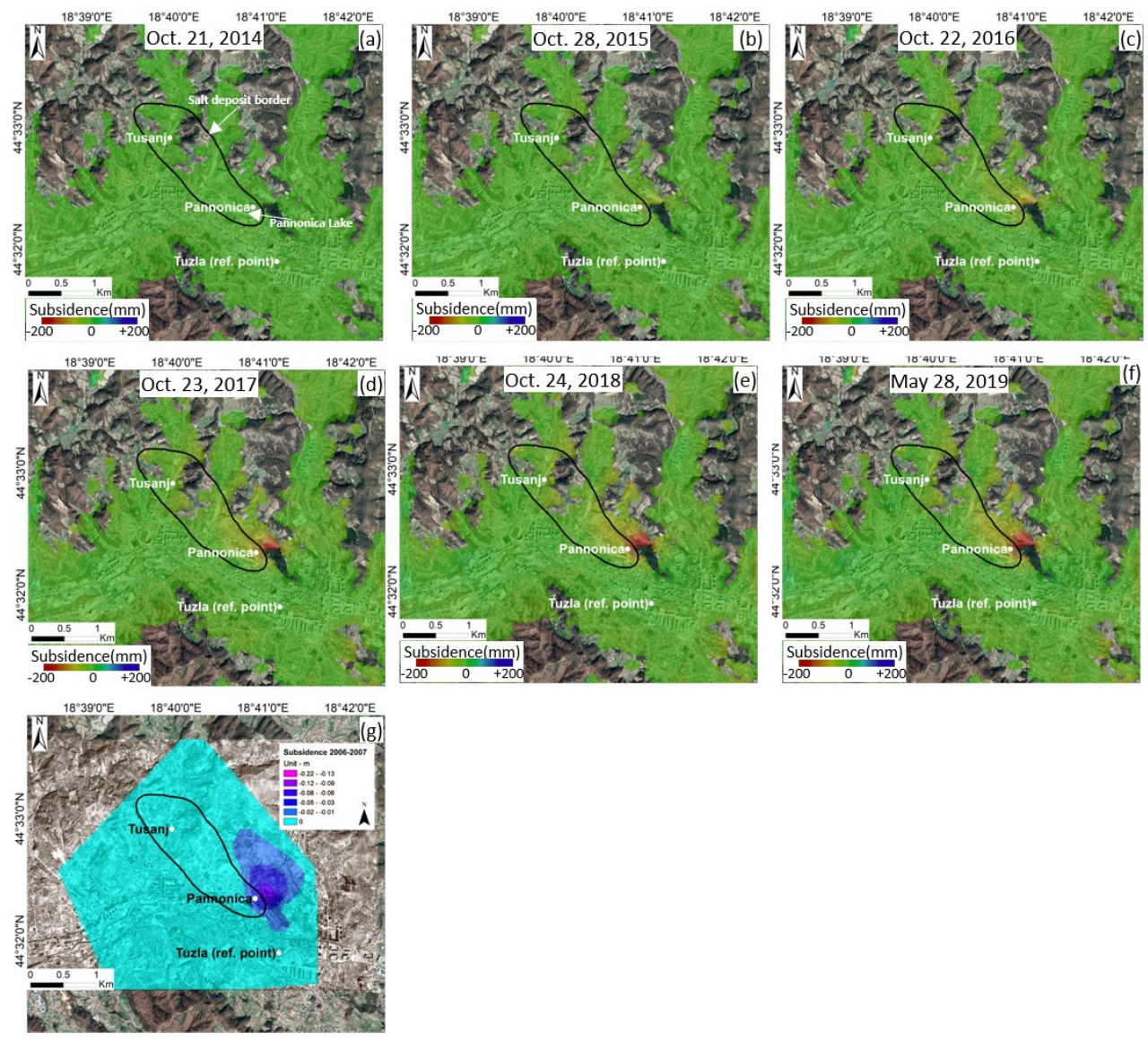

Fig. 5. Spatial distribution of subsidence in Tuzla City: (a)-(f) subsidence obtained by SBAS-DInSAR from October 9, 2014 to May 28, 219 and (g) subsidence obtained by static GPS survey from 2006 to 2007 [2]. 


\subsection{Comparison of the results of SBAS-DInSAR and kinematic GNSS}

A real-time kinematic GNSS monitoring system has been installed at this site for subsidence monitoring. It is composed of two measurement stations (Tusanj and Pannonica stations) and one reference station (Tuzla station) (Fig. 5) [5]. The displacements obtained by the GNSS monitoring system are used to validate the results obtained by SBASDInSAR. In order to make an appropriate comparison, the three-dimensional displacements obtained by GNSS are projected into the direction of LOS [8]. The LOS direction in this case is in respect to the descending orbit direction and the right-looking SAR sensor direction.

The LOS displacements obtained by SBAS-DInSAR are extracted from the pixels of the ground surface including the points of the GNSS stations. Fig. 6 shows a comparison of the LOS displacements between SBAS-DInSAR and GNSS.
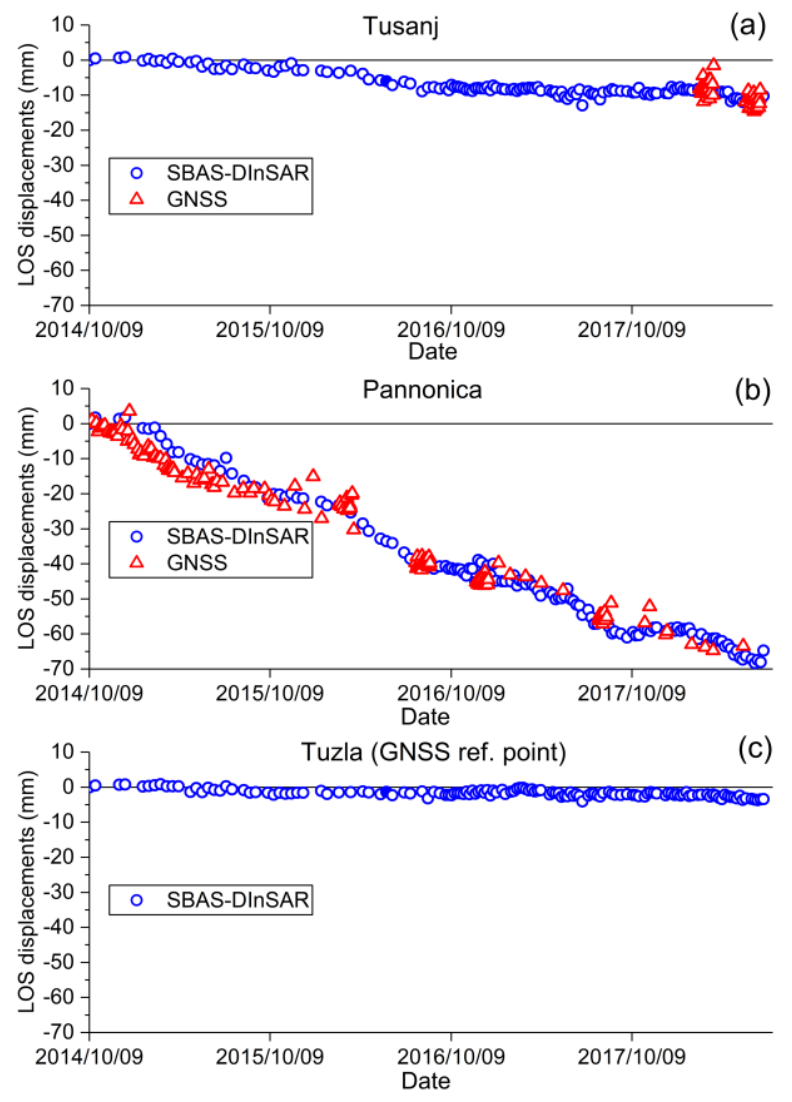

Fig. 6. Locations of LOS displacements obtained by SBAS-DInSAR and GNSS monitoring system:

(a) GNSS stations, (b) Pannonica station, (c) Tusanj station, and (d) Tuzla station (the reference point of the GNSS monitoring system).

The GNSS results at Tusanj station were quite limited due to the scattered data. However, the results of SBAS-DInSAR and GNSS show a good agreement. The total measured displacement at Tusanj station from October 9, 2014 to July 2, 2018 is very small, namely, up to $-20 \mathrm{~mm}$.

The largest displacements are detected in the area of Pannonica station. SBAS-DInSAR shows that the displacement is up to $-70 \mathrm{~mm}$ from October 9, 2014 to July 2, 2018. The GNSS results at Pannonica station also show a similar trend in displacement and similar 
behavior to the SBAS-DInSAR results. The discrepancy between the results is less than 10 $\mathrm{mm}$.

SBAS-DInSAR confirms that the reference point for the GNSS monitoring system (Tuzla station) is in a stable area. The total displacement in this area is less than $-5 \mathrm{~mm}$ for 3.7 years (from October 9, 2014 to July 2, 2018).

\subsection{Temporal transition of subsidence obtained by DInSAR}

After confirming the validity of the SBAS-DInSAR results in section 3.2, the transition of the subsidence at selected points is presented in this section. The locations of the selected points are presented by Fig. 7a. The temporal evolution of the subsidence obtained by SBAS-DInSAR at selected points (P-5, ..., P-25) from October 9, 2014 to May 28, 2019 are presented by Fig. $7 \mathrm{~b}$.
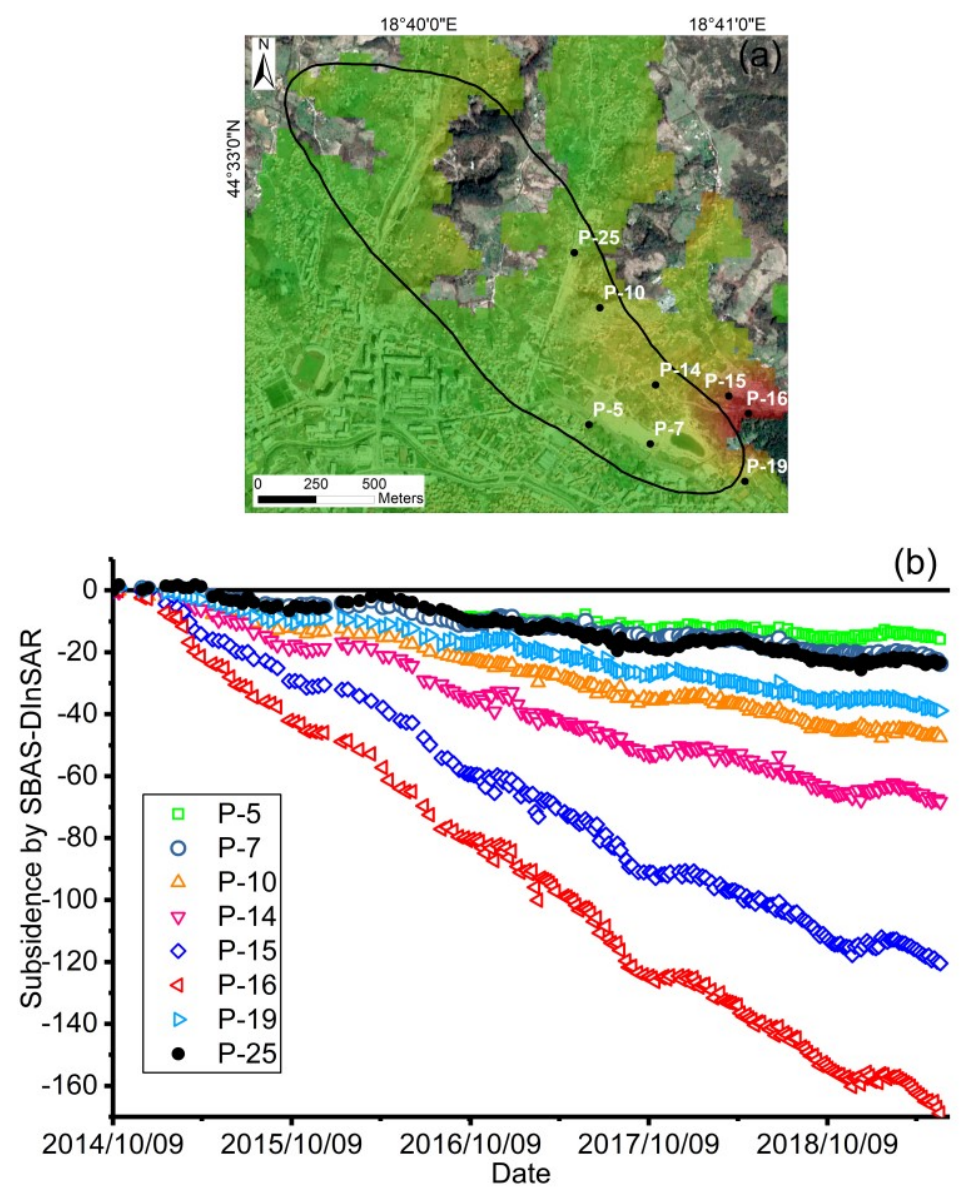

Fig. 7. Time transition of the subsidence obtained by SBAS-DInSAR at several points: (a) locations of the points and (b) the subsidence transition for each point.

The highest accumulated subsidence was found at P-16, about $-170 \mathrm{~mm}$ for 4.6 years ($36.4 \mathrm{~mm} /$ years $)$, and the smallest one was detected at P-5, about $-16 \mathrm{~mm}(-3.4 \mathrm{~mm} / \mathrm{years})$. P-16 is located northeast of Pannonica Lake, where the GPS results (2006-2007) also show that the subsidence is still continuing in this area. P-5 is located at the edge of the border of the salt deposit and a bit far from the center of the subsidence area. 


\section{Conclusions}

The results of an application of SBAS-DInSAR for subsidence monitoring, due to underground brine extraction in Tuzla City, Bosnia and Herzegovina, have been presented in this research. Through the use of SBAS-DInSAR, it was found that the maximum subsidence rate obtained at a point was $-36.4 \mathrm{~mm} /$ year for 4.6 years (from October 9, 2014 to May 28, 2019). The accuracy and validity of the SBAS-DInSAR method was examined by comparing the results with those of the GNSS kinematic method. The discrepancy between the results (SBAS-DInSAR and GNSS) was less than $10 \mathrm{~mm}$.

Since SBAS-DInSAR was able to provide accurate results for both distribution and transition, this method is recommended as an effective tool for use in continuous subsidence monitoring.

The authors express their gratitude to the European Space Agency (ESA) for providing the Sentinel-1 SAR data free of charge. This research was partially supported by JSPS KAKENHI Grant Number 16H03153.

\section{References}

1. F. Mancini, F. Stecchi, G. Gabbianelli, Environmental Geology 58(2), 381-389 (2009)

2. F. Stecchi, Tuzla City (BIH): An example of geohazard induced by salt extraction (Doctoral dissertation, University of Bologna, 2008)

3. F. Mancini, F. Stecchi, G. Gabbianelli, Engineering Geology 109(3-4), 170-182 (2009)

4. P. Berardino, G. Fornaro, R. Lanari, E. Sansosti, IEEE Transactions on Geoscience and Remote Sensing 40(11), 2375-2383 (2002)

5. R. Čeliković, E. Imamović, International Symposium on Engineering Geodesy, 489498 (2016)

6. Z. Ferhatbegovic, Geological features of the central part of the Tuzla basin (Doctoral dissertation, University of Tuzla, 2004)

7. R.F. Hanssen, Radar Interferometry: Data Interpretation and Error Analysis (Kluwer Academic Publisher, 2001)

8. L. He, L. Wu, S. Liu, Z. Wang, C. Su, SN. Liu, Remote Sensing 7(9), 12440-12458 (2015) 